\title{
The Safety Compliances of Footwear Industries in Bangladesh
}

\author{
Md. Farhad Ali \\ Associate Professor, \\ Institute of Leather Engineering and Technology, \\ University of Dhaka, 44-50 Hazaribagh, Dhaka-1209, \\ Bangladesh
}

\author{
Mukta Rani Sarkar \\ Student, \\ Institute of Leather Engineering and Technology, \\ University of Dhaka, 44-50 Hazaribagh, Dhaka-1209, \\ Bangladesh
}

\author{
Md. Arafat Hossain \\ Student, \\ Institute of Leather Engineering and Technology, \\ University of Dhaka, 44-50 Hazaribagh, Dhaka-1209, \\ Bangladesh
}

\begin{abstract}
Footwear industries in Bangladesh are regarded as an influential sector to get a strong economic status. Compliance is the totality of rules, regulation operating in a working place of which an employer and an employee are bound to obey; some of them are either mandatory or directory. It has become a major concern for organizations and businesses. It is regulated by safety compliance companies or organizations, as well as government legislation, and is monitored and enforced by these bodies to ensure compliance with the established standards. Enforcing compliance means ensuring that the business adheres to the regulations stated. It implies conforming to a specification, standard or law that has been clearly defined. It may include documenting processes, procedures, conditions, and changes. It often requires planning and actions to maintain. The aim of my article is to evaluate the safety compliance status of footwear industries in Bangladesh and bring the attention of entrepreneurs and workers regarding safety compliance. It is easier to maintain compliance than to regain compliance.
\end{abstract}

Keywords: Compliance, regulations, evaluate, entrepreneurs.

\section{INTRODUCTION}

Footwear industries are subsectors of leather getting priority from the government as for their high value addition (Amal et al. 2018). Footwear sector of Bangladesh is playing an important role in export sector as well as forward movement of our country's economy. Due to good product quality, availability of raw material, low labor cost, and exchange rate advantage, Bangladesh has become a striking target for investors (Amal et al. 2018). In 2017, Bangladesh exported about $\$ 632.5$ million leather shoes which was about $1.2 \%$ of world total export (Workman, 2018). Increasing business competition, rapidly advancing technology, and changing workforce characteristics are all pressing issues for the entire economic system (James, 2003). The future competitiveness in the footwear industry would depend on adjustment with rising operational cost towards maintaining compliance (Mehedi et al. 2015). According to ILO (2014) occupational hazard lies as the hazardous genesis of almost all fatalities in industrialized generation, over the 2.3 million fatalities that take place annually, over 2 million fatalities are caused by work related diseases (Zakir et al. 2017). There is no doubt that safety at work is one of the major concerns of industries (Subramaniam et al. 2016). To achieve sustained decent working conditions and strong preventive safety compliance is the key element (Alli, 2008).

\section{MATERIALS AND METHODS}

A. Study area

The study area is comprised of tannery area in Gazipur. It is the part of Dhaka, the capital of Bangladesh. It is residing between $23^{\circ} 53^{\prime}$ to $24^{\circ} 21^{\prime}$ north latitudes and $90^{\circ} 09^{\prime}$ to $92^{\circ} 39^{\prime}$ east longitudes. The study was performed for two industries of this area.

\section{List of the industries}

1. Apex Footwear Ltd.

2. FB Footwear Ltd.

\section{RESULT AND DISCUSSION}

\section{A. Basic Requirements of Safety Compliances}

According to the order of the govt. and fire service as well as civil defense which safety measurement should take in the industries those is-

1. There should have two power point in each floor and for every fire point it needs a water full dram (45 gallon) and four bucket should be hanged up.

2. For electric fire on the floor of factory there should have carbon di oxide (main switch, sub-main switch for distribution board it's need per one) and other fire there have DCP fire cooler machine (At least one for $1000 \mathrm{sq}$ ft.).

3. Emergency stairs should be made (wide 45 inch and $45^{\circ}$ angle step.

4. During the working period all stairs including substitute should be open on. 
5. There will be no obstacles on the stairs and in the way of industry.

6. Emergency lighting system should be kept in the industry and in the way of industry.

7. Hanging wires need to be changed and electric wires should be conduit or concealed.

8. In the industry there should be 18 fire fighters per 100 people.

9. Hose reel and smoke detector should be set up.

10. Public Announcement system (P.A) should be set up.

11. Yellow color dress should be donated by fire fighters.

12. Adequate medicine and first aid box should be provided.

13. To keep "Fire Hook" in the industry.

14. On every floor, at least a quit should be put in the industry.

15. Electric connection should not kept in the bonded ware house / in the store.

16. Telephone number of fire service, police station and electric sector adjacent to the industry should be preserved in a particular place.

(a) Chemical Safety includes-

General caution:

- Don't eat, drink or smoke near chemicals.

- Don't hurry or rush - carelessness can cause accidents.

- Bring the smallest quantity of chemicals needed for a job outside of storage rooms or chemicals.

- Keep work areas clean to eliminate potential accidents and fires, good housekeeping is more than just sweeping the floor and wiping off machines and equipment.

Preventive measures:

- Store chemicals properly and keep chemical containers covered.

- Ventilate chemical stores and work areas to avoid accumulation of vapor, fume, mist etc.

- Ensure proper maintenance and lubrication of machines.

- Prohibit smoking in fire prone areas, such as chemical stores.

(b) Fire Safety includes-

Points to be noted:

- There should be at least two exits in every room at opposing sides.

- Exits should be clearly marked, unobstructed, unlocked and easy to open.

- There should be fire alarms on each floors and emergency lights placed above exits and stairwells.

- The ration of the extinguisher should not be less than 1 per 1000 square feet and travelling distance from work station to extinguishers should not be more than 75 feet.

- Fire extinguishers locations should be marked properly and fire extinguisher operation instruction should be posted with extinguishers in local language.

- Direction of fire evacuation plan to be posted throughout the industry.

Preventive measures:

- $\quad$ Fire extinguishers should be checked periodically.

- A "Yellow Box" or other marking should be in front of all fire-fighting equipment, control panels and potential fire source areas indicating areas to be kept clear at all times.

\section{(c) Operational Safety includes-}

General notes:

- Machines may only be operated by adequately trained operators and only after having completely read and understood the instruction manual.

- The danger and safety instructions on the machine itself are to be followed.

- Everyday maintenance work is only to be carried out by appropriately trained personnel.

- Repairs and special maintenance work may only be carried out by qualified service staff or appropriately trained personnel.

- Work on electrical equipment may only be carried out by appropriately trained personnel.

- Work is not permitted on parts and equipment which are connected to the power supply.

- Modifications and alterations to the machine may only be carried out under observance of all the relevant safety regulations.

Preventive measures:

- The Instruction Manuals are component part of machines and must be available to the operating personnel at all times.

- The Instruction Manual must be read before operating machines for the first time.

- The operating and specialist personnel is to be instructed as to the safety equipment of machines and regarding safe work methods.

\section{B. Questionnaires}

The questionnaires were prepared to evaluate the safety compliances of footwear industries.

1. Do the workers wear apron and safety glass during working?

2. Do the workers use mask and hand gloves during working?

3. Do the workers wear safety footwear while operating different machine and also different operation?

4. Do the workers get sufficient light and air supply during operating different machine and also different operation?

5. Is the room temperature right during operating different machine and also different operation in that room?

6. Does Material Safety Data Sheet (MSDS) in local language hanged or not in all operation, machines and chemicals? 
7. Whether industry has separate storage for flammable chemical?

8. Whether industry has separate storage for hazardous materials like thinner, primer, adhesive finishes?

9. Whether industry has filter system drinking water facility for the workers?

10. Whether industry has ventilation system to reduce the temperature of the industry?

11. Are all containers properly labeled (chemical name, type of hazard, special precautions and emergency information)?

12. Does the industry provide adequate aisle space in all storage areas for easy access, transfer and inspection?

13. Are the chemical storage areas clean and orderly?

Survey-01:

Name of the Industry: Apex Footwear Ltd.

Number of Manpower: 8,400

Production capacity: 20,000 pair shoes/day

\begin{tabular}{|c|c|c|c|}
\hline Question No & N/A & Yes & No \\
\hline 1. & & $\sqrt{ }$ & \\
\hline 2. & & $\sqrt{ }$ & \\
\hline 3. & & $\sqrt{ }$ & \\
\hline 4. & & $\sqrt{ }$ & \\
\hline 5. & & $\sqrt{ }$ & \\
\hline 6. & & $\sqrt{ }$ & \\
\hline 7. & & $\sqrt{ }$ & \\
\hline 8. & & $\sqrt{ }$ & \\
\hline 9. & & & \\
\hline 10. & & & \\
\hline 11. & & & \\
\hline 12. & & & \\
\hline 13. & & & \\
\hline
\end{tabular}

Survey-02:

Name of the Industry: FB Footwear Ltd.

Number of Manpower: 2,300

Production capacity: 5,000 pair shoes/day

\begin{tabular}{|c|c|c|c|}
\hline Question No & N/A & Yes & No \\
\hline 1. & & $\sqrt{ }$ & \\
\hline 2. & & $\sqrt{ }$ & \\
\hline 3. & & $\sqrt{ }$ & \\
\hline 4. & & $\sqrt{ }$ & \\
\hline 5. & & $\sqrt{ }$ & \\
\hline 6. & & $\sqrt{ }$ & \\
\hline 7. & & $\sqrt{ }$ \\
\hline 8. & & $\sqrt{ }$ \\
\hline 9. & & & \\
\hline 10. & & $\sqrt{ }$
\end{tabular}

\begin{tabular}{|c|c|c|c|}
\hline 11. & & $\sqrt{ }$ & \\
\hline 12. & & $\sqrt{ }$ & \\
\hline 13. & & $\sqrt{ }$ & \\
\hline
\end{tabular}

\section{Points to be extracted from the study}

1. Export oriented industries and established footwear industries in Bangladesh maximum follow the safety compliance.

2. Now-a-days small and medium footwear industries becoming more concern about safety compliance.

3. Most of the footwear industries are not enough concern about chemical handling and using operational safety.

\section{CONCLUSION}

There are many laws that govern most industries. Decent work and fair globalization are important. Everybody must enjoy basic worker's right, work in an environment where standards are respected and receive their share of the wealth created. Diversity and pro-active compliance especially There with the national law will boost the footwear sector in Bangladesh which given its value and contribution to the national income. It is important to concern about safety compliance for the future business, because in future the industrial compliance will get more rigorous in attitude for export market.

\section{ACKNOWLEDGEMENT}

We wish to express our sincere gratitude to all of those respondents from the sample industries who executed countless co-operations during this study.

\section{REFERENCES}

[1] Alli BO (2008): Fundamental Principles of Occupational Health and Safety, International Labour Office Geneva PP: 1-227

[2] Ansary, M. A., Barua, U. (2015): Workplace safety compliance of RMG industry in Bangladesh: Structural assessment of RMG factory buildings; Article (PDF Available) in International Journal of Disaster Risk Reduction; DOI: 10.1016/j.ijdrr.2015.09.008

[3] Chandrakantan, S., Faridahwati, S. M., Md, Z. M. L. Subramaniam, R. S., Zuraida, H. (2016): Safety Management Practices and Safety Compliance: A Model for SMEs in Malaysia; ISSC 2016: International Soft Science Conference; Available at: http://dx.doi.org/10.15405/epsbs.2016.08.120

[4] Deb, A. K., Chowdhury, M., Hossain, M. I., Sarker, M. R. (2018) Assessment of Noise, Temperature, Light Intensity And Their Impacts on Workers In Footwear And Leather Products Industries of Bangladesh, Journal of Environmental Science, Toxicology and Food Technology, Vol. 12, Issue 3 Ver. I, PP 25-31.

[5] Deb, A. K., Chowdhury, M., Azam, F. A. B., Hossain, M. I (2018): Workers' Health and Workplace Condition Evaluation (WCE) Of the Footwear Industries in Bangladesh, IOSR Journal of Environmental Science, Toxicology and Food Technology (IOSR-JESTFT) e-ISSN: 2319-2402, p- ISSN: 2319 2399.Volume 12, Issue 8 Ver. I, PP 07-13, www.iosrjournals.org, DOI: $10.9790 / 2402-1208010713$

[6] D. Workman, Leather Shoes Exports by Country, www.worldstopexports.com , May 11, 2018

[7] James O. Wright, Evaluation of workplace safety performance: a case study auditing process (2003); Available at: https://lib.dr.iastate.edu/rtd

[8] Khan, M. Z. H. (2017): A Case Study on Occupational Health and Safety of Footwear Manufacturing Industry, IASET: Journal of Business and General Management (IASET: JBGM); ISSN (P) Applied; ISSN (E): Applied; Vol. 2, Issue 1, 1-6 